\title{
Entrevista com Martin Chalfie: prêmio Nobel de Química
}

\author{
por Lilian L. N. Guarieiro
}

Data de publicação na Web: 23 de Dezembro de 2011
Recebido em 14 de Dezembro de 2011
Aceito para publicação em 23 de Dezembro de 2011

ascido em Chicago (1947), o Professor Chalfie ingressou, em 1982, na Universidade de Columbia como Professor do Departamento de Ciências Biológicas e, em 2004, foi eleito membro da Academia Nacional de Ciências dos EUA. Em 2008, ele dividiu o Prêmio Nobel de Química com Roger Tsien e Osamu Shimomura pela descoberta e desenvolvimento da proteína verde fluorescente (GFP). Chalfie demonstrou o valor da GFP como um marcador genético luminoso para vários fenômenos biológicos, permitindo que proteínas específicas fossem localizadas e rastreadas em organismos vivos. Como resultado do trabalho destes três cientistas, a GFP tornou-se uma das ferramentas mais importantes da biociência contemporânea. ${ }^{1}$

Em homenagem ao Ano Internacional da Química (AIQ), os editores da $\mathrm{RVq}$ convidaram a Professora Lilian Guarieiro da Faculdade de Tecnologia SENAI CIMATEC e pesquisadora do Instituto
Nacional de Ciência e Tecnologia de Energia e Ambiente (INCT-EA) para entrevistar o Professor Martin Chalfie, durante sua visita a Salvador, Bahia, quando ele proferiu, a convite da Sociedade Brasileira de Química e do INCT-EA, em comemoração ao AIQ, (Figura 1), a conferência intitulada "Proteína Fluorescente Verde (GFP)", no Salão Nobre da reitoria da Universidade Federal da Bahia (UFBA).
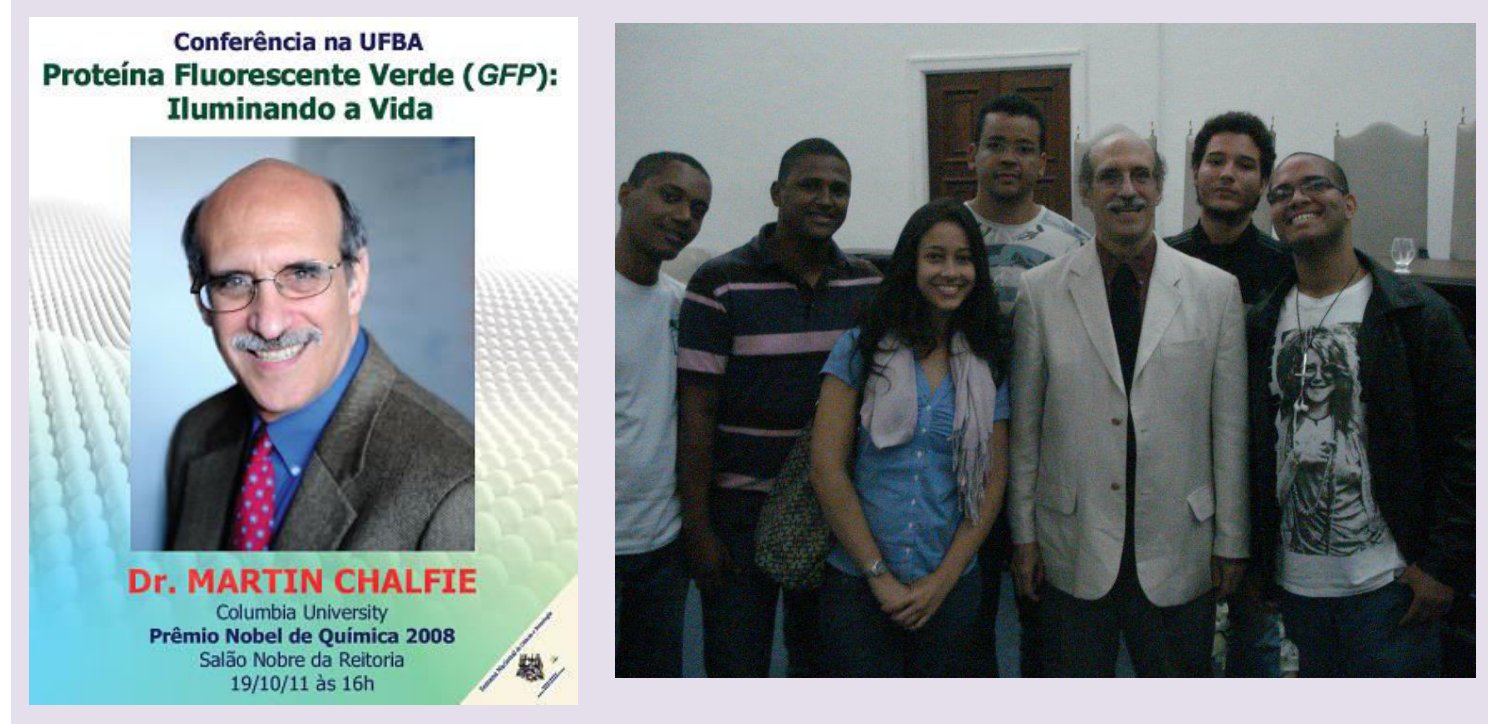

Figura 1. Cartaz convite da conferencia do Prof. Martin Chalfie na Reitoria da UFBA, Salvador-BA; Foto dos estudantes de Química com o Prof. Chalfie após sua conferência

\section{Entrevista com Martin Chalfie}

Após a excelente conferência "Proteína Fluorescente Verde (GFP): lluminando a Vida", o Professor Martin Chalfie foi entrevistado pela Professora Lílian Guarieiro, quando fez questão de enfatizar a importância da pesquisa básica e do seu compromisso como prêmio Nobel em divulgar ciência (Figura 2). A entrevista transcorreu com muita espontaneidade e abordou dúvidas e curiosidades, principalmente, dos estudantes sobre as ideias de um Prêmio Nobel e qual a sua reação ao receber a notícia do prêmio.

$R V q$ - Quando você imaginou a possibilidade de utilizar GFP em sua pesquisa? Em algum momento você pensou que sua ideia fosse se concretizar e que você teria a chance de ganhar um Premio Nobel?
Chalfie - Quando eu tive a ideia de usar a GFP como marcador biológico, naturalmente, esperava que desse certo, e eu sabia que se o fizesse, a GFP iria ser uma ferramenta muito útil. No entanto, na época, eu não associei minha pesquisa a um prêmio Nobel.

$R V q$ - Como você recebeu a notícia que havia ganhado o Prêmio Nobel de Química e qual foi a sua primeira reação? 
Chalfie - Moro em um apartamento, e na ocasião em que recebi a notícia do prêmio Nobel só havia um telefone na cozinha, que fica separada por duas portas do meu quarto. Como resultado, eu não acordei quando recebi o telefonema da Suécia. Pouco depois das 6:00 horas da manhã,

acordei e fiquei curioso em saber quem tinha ganhado o Prêmio de Química e fui conferir no site da www.nobelprize.org. Fiquei bastante surpreso ao ver meu nome. Acordei minha esposa mostrando-lhe o site e disse: "Aconteceu!" Demos vários pulos de alegria.

$R V q$ - No desenvolvimento de suas pesquisas é comum você se deparar com artigos de pesquisadores brasileiros? Existe algum pesquisador brasileiro ou linhas de pesquisa que estão sendo desenvolvidas no Brasil que você destacaria?

Chalfie - A minha principal linha de pesquisa é o estudo do desenvolvimento e função do sistema nervoso utilizando o nematoide Caenorhabditis elegans. Poucos pesquisadores no Brasil desenvolvem seus trabalhos com este organismo. Como resultado, eu não tinha conhecimento sobre as pesquisas feitas no Brasil antes de visitar, em 2009, o país. Durante minha visita ao Brasil, tive a oportunidade de me reunir com cientistas brasileiros e ouvir sobre suas pesquisas. Atualmente, tenho ouvido falar sobre estudos da doença reumática do coração e dos efeitos da melatonina sobre parasitas da malaria; e, agora, sobre os estudos interdisciplinares da Baía de Todos os Santos. Artigos nas revistas Nature e Science também têm descrito aspectos mais gerais sobre pesquisas que vêm sendo desenvolvidas no Brasil.

$R V q$ - Embora os pesquisadores brasileiros desenvolvam estudos de ele gosta de começar novas áreas de pesquisa. Como eu o considero um dos cientistas mais surpreendentes do nosso tempo, este é provavelmente um bom conselho.

$R V q$ - Atualmente, nós brasileiros estamos muito preocupados com a relação "Universidade $x$ Indústria". Acreditamos que esta relação pode contribuir para Professor Chalfie

alto impacto, até o momento o Brasil não teve um ganhador do prêmio Nobel. O que você acha que está faltando para um brasileiro ser laureado?

Chalfie - Eu não acredito que o objetivo deva ser um Nobel. Acredito, sim, que a ênfase deva ser no fornecimento de oportunidades locais (financiamento e liberdade para a investigação de ciência básica) que permitam que descobertas sejam feitas. Em conversa com pesquisadores do Brasil, pude perceber que essas oportunidades existem. A infra-estrutura científica está presente e os prêmios e o reconhecimento virão.

$R V q$ - Qual é o segredo para ser vencedor de um Prêmio Nobel?

Chalfie - Eu gostaria de saber o segredo. Não tenho certeza se alguém realmente sabe o segredo, já que o Nobel é, geralmente, dado para trabalhos que tenham grande impacto científico. Eu não acredito que alguém possa prever o impacto de sua pesquisa. Meu orientador de pósdoutorado, Sydney Brenner, que venceu 0 Prêmio de Medicina/Fisiologia em 2002, disse que uma pesquisa pode ser desenvolvida de três maneiras: terminar um assunto fornecendo a resposta definitiva; iniciar uma nova área de pesquisa; e trabalhar em um projeto de pesquisa. Para ele, o primeiro é quase impossível e o último não é interessante. Como resultado, caminhar com maior velocidade no desenvolvimento de novas tecnologias, através da investigação e inovação. Como é esta relação em seu país e você acha que este é realmente o caminho?

Chalfie - Aplicações industriais são muito importantes, mas sinto que a pesquisa básica é a norteadora da inovação. Uma vantagem de eu estar em uma Universidade é que eu tenho a liberdade de escolher a área de pesquisa em que irei trabalhar. Apesar de existir várias exceções (por exemplo, o Bell Labs), sinto que a liberdade de trabalhar em pesquisa básica oferecida pelas Universidades permite as descobertas que serão aplicadas na indústria.

$R V q$ - 2011, eleito para ser o Ano Internacional da Química, foi um ano em que muitos pesquisadores tiveram o compromisso de desenvolver ações importantes para mostrar a importância da química para o nosso planeta. Você acha que estamos conseguindo atingir as metas e os objetivos para a celebração do Ano Internacional da Química? Que ações você gostaria de destacar?

Chalfie - Eu não tenho como saber qual o impacto do Ano Internacional da Química, mas eu fiquei muito impressionado com os esforços feitos em muitos países para aumentar a conscientização das pessoas sobre a ciência, e a química em particular. No Brasil, eu gostei, especialmente, de ouvir que existe uma semana 
dedicada à divulgação da Ciência e Tecnologia e também sobre o programa Ciência sem Fronteiras.

$R V q$ - Que mensagem você deixaria aos jovens pesquisadores do Brasil, para que eles possam ter uma carreira bem sucedida como a sua?

Chalfie - Minha experiência com jovens investigadores é que eu aprendo muito mais do que ensino. Então, eu não tenho certeza se realmente existe uma mensagem diferente para dizer que, fazer ciência pode ser muito frustrante (a maioria dos experimentos não funcionam), mas que a paixão e o entusiasmo de se fazer pesquisa compensam todos os momentos difíceis.

Agradecimentos
Gostaria de agradecer a gentileza do Professor Martin Chalfie em nos proporcionar a entrevista, ao INCT-EA, $\mathrm{CNPq}$ e à RVq pelo convite.

\section{Referências bibliográficas}

${ }^{1}$ de Farias, F. M. C. Rev. Virtual de Quim 2009, 1, 2. [Link]

* SENAI CIMATEC - Centro Integrado de Manufatura e Tecnologia. 41650-010, Salvador-BA, Brasil e INCT Energia e Ambiente, UFBA. 40170-290, Salvador-BA, Brasil. 